\title{
Numerical Taxonomy of Bacteria from the Beaufort Sea
}

\author{
By TATSUO KANEKO,* MICAH I. KRICHEVSKY AND \\ RONALD M. ATLAS \\ Department of Biology, University of Louisville, \\ Louisville, Kentucky 40208, U.S.A. \\ and \\ Microbial Systematics Unit, National Institute of Dental Research, \\ National Institutes of Health, Bethesda, Maryland 20014, U.S.A.
}

(Received 12 April 1978; revised 21 June 1978)

\begin{abstract}
Taxonomic and ecological studies were done on 553 bacterial strains isolated in late summer 1975 from the Arctic Beaufort Sea. Numerical taxonomic analyses were employed using 300 features, assessing similarity by the Jaccard coefficient $\left(S_{J}\right)$ and clustering the strains using single linkage. Bacteria isolated at $4{ }^{\circ} \mathrm{C}$ ( 14 clusters) and $20^{\circ} \mathrm{C}$ (13 clusters) were compared with previously described genera. The dominant bacteria in the Beaufort Sea appear to be different from those found in temperate marine environments. Orangepigmented bacteria, which appear to be Flavobacterium species, were dominant in surface water. Several taxonomic clusters of presumed Vibrio species were found. Many of the Gram-negative rods were highly pleomorphic and could not be identified. Some isolates resembled morphologically the genus Microcyclus. Feature analyses showed evidence of adaptation to the environment. All bacterial isolates were psychrophilic or psychrotrophic. Nutritionally, most of the organisms required organic growth factors such as vitamins.
\end{abstract}

\section{INTRODUCTION}

Microbiological studies in the Arctic Ocean are rare. As part of the U.S. Outer Continental Shelf Environmental Assessment Program, we began intensive studies on the ecology of micro-organisms in the Beaufort Sea. A major purpose of this undertaking is to characterize the microbiological communities, quantitatively and qualitatively, before mineral resources of the Alaskan Continental Shelf are extensively developed. Extensive data were gathered to characterize the predominant bacterial populations both taxonomically and ecologically. We believe that this is the first such study on bacteria in the Arctic Ocean.

This paper reports the results of sampling during summer 1975. During a normal summer, ice recedes about $80 \mathrm{~km}$ from the shore but shorefast ice remained throughout 1975 . This restricted sampling to nearshore areas. Thus, our study was of the bacterial community during a summer with severe ice conditions. Different results might have been obtained during a more typical summer.

\section{METHODS}

Sample collection and bacterial isolation. Samples were collected in the Beaufort Sea (Fig. 1) during late summer 1975 (Aug. 20 to Sept. 25). Water samples were collected with a sterile Niskin sampler (General Oceanics, Miami, Fla., U.S.A.) and sediment samples with a mud grabber (Kahl Scientific, San Diego, Calif., U.S.A.). Samples were transferred to sterile containers, stored with ice and processed within a few hours. Temperature and salinity were measured (Table 1) with a salinity meter (Yellow Springs Instrument Co., Yellow Springs, Ohio, U.S.A.).

* Present address: Kelco Division of Merck and Co., Inc., San Diego, California 92123, U.S.A. 


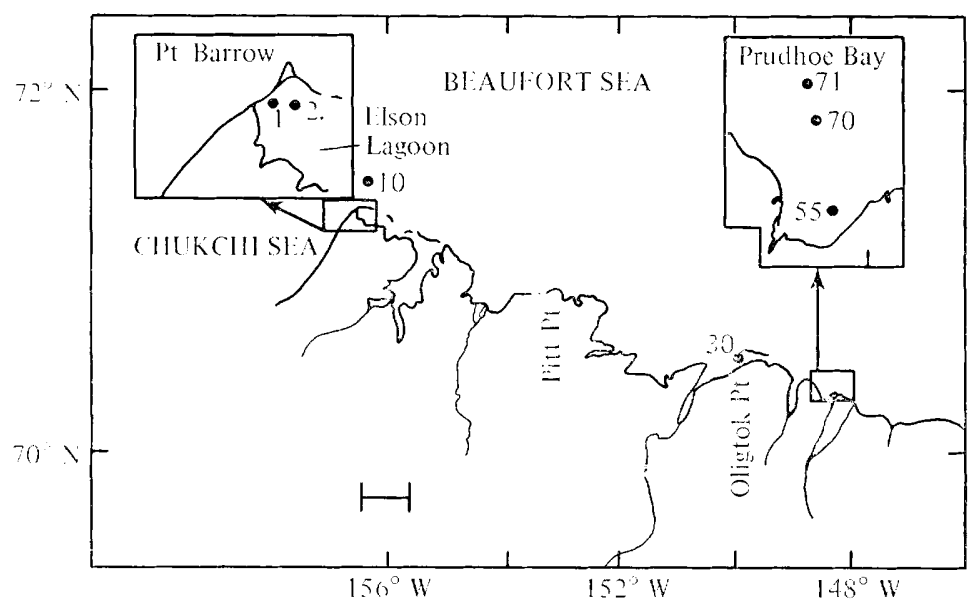

Fig. 1. Chart of sampling area. Numbers indicate sampling stations. Bar marker represents 20 nautical miles.

Table 1. Abiotic parameters and viable counts

\begin{tabular}{|c|c|c|c|c|c|}
\hline \multirow{2}{*}{$\begin{array}{c}\text { Station } \\
\text { (see Fig. 1) }\end{array}$} & \multirow{2}{*}{$\begin{array}{l}\text { Depth } \\
(\mathrm{m})\end{array}$} & \multirow{2}{*}{$\begin{array}{c}\text { Temp. } \\
\left({ }^{\circ} \mathrm{C}\right)\end{array}$} & \multirow{2}{*}{$\begin{array}{c}\text { Salinity } \\
(\%)\end{array}$} & \multicolumn{2}{|c|}{ Viable count* after incubation a } \\
\hline & & & & $4^{\circ} \mathrm{C}$ & $20^{\circ} \mathrm{C}$ \\
\hline \multicolumn{6}{|c|}{ Water samples } \\
\hline 1 & $1 \cdot 0$ & -0.5 & $22 \cdot 0$ & $3 \cdot 5 \times 10^{3}$ & $3.9 \times 10^{3}$ \\
\hline 2 & $1 \cdot 0$ & -0.5 & $22 \cdot 2$ & $1.4 \times 10^{3}$ & $5 \cdot 7 \times 10^{2}$ \\
\hline $1 \overline{0}$ & $1 \cdot 0$ & -0.5 & $23 \cdot 8$ & $4 \cdot 8 \times 10^{3}$ & $4.4 \times 10^{2}$ \\
\hline 30 & $1 \cdot 0$ & $1 \cdot 9$ & $12 \cdot 1$ & $1.0 \times 10^{4}$ & $8.5 \times 10^{3}$ \\
\hline 55 & $1 \cdot 0$ & $1 \cdot 5$ & $16 \cdot 0$ & $2 \cdot 1 \times 10^{4}$ & $1.9 \times 10^{4}$ \\
\hline 70 & $1 \cdot 0$ & $1 \cdot 5$ & $18 \cdot 5$ & $9 \cdot 2 \times 10^{3}$ & $6.9 \times 10^{3}$ \\
\hline 71 & $1 \cdot 0$ & $0 \cdot 3$ & $20 \cdot 2$ & $5.9 \times 10^{3}$ & $3 \cdot 8 \times 10^{3}$ \\
\hline \multicolumn{6}{|c|}{ Sediment samples } \\
\hline 1 & $2 \cdot 3$ & -0.5 & - & $1.0 \times 10^{5}$ & $1.1 \times 10^{5}$ \\
\hline 2 & $2 \cdot 3$ & -0.5 & - & $1 \cdot 1 \times 10^{5}$ & $1 \cdot 1 \times 10^{5}$ \\
\hline 10 & $9 \cdot 3$ & 0.8 & - & $5 \cdot 3 \times 10^{4}$ & $1.3 \times 10^{4}$ \\
\hline 30 & $2 \cdot 0$ & $1 \cdot 8$ & - & $8.7 \times 10^{4}$ & $2.5 \times 10^{5}$ \\
\hline 55 & $3 \cdot 3$ & $1 \cdot 5$ & $20 \cdot 0$ & $2 \cdot 3 \times 10^{5}$ & $3.6 \times 10^{5}$ \\
\hline 70 & $6 \cdot 7$ & $0 \cdot 3$ & $21 \cdot 5$ & $6.8 \times 10^{4}$ & $1.8 \times 10^{5}$ \\
\hline 71 & $6 \cdot 3$ & $0 \cdot 1$ & $21 \cdot 3$ & $9 \cdot 7 \times 10^{4}$ & $1.6 \times 10^{5}$ \\
\hline
\end{tabular}

* Expressed as numbers $\mathrm{ml}^{-1}$ for water samples and numbers ( $\mathrm{g}$ dry wt sediment $)^{-1}$ for sediment samples.

Serial dilutions of samples were made in Rila marine salts solution (Rila Products, Teaneck, N.J., U.S.A.) and plated on marine agar 2216 (Difco). All materials were cooled to $5{ }^{\circ} \mathrm{C}$ before plating. For each sample, one set of replicate plates was incubated at $4{ }^{\circ} \mathrm{C}$ for 3 weeks and another at $20^{\circ} \mathrm{C}$ for 2 weeks. Colonies were counted with the aid of a stereomicroscope $(30 \times)$. The mean count from triplicate plates was recorded for each dilution and temperature (Table 1).

All colonies were numbered sequentially. Using random number tables, about 60 bacterial colonies from each sample were selected for isolation. After subculturing twice on marine agar to ensure purity and viability, about 25 strains from each sample were randomly selected for numerical taxonomic testing. They were maintained on marine agar slants at $4^{\circ} \mathrm{C}$ and subcultured monthly. Some strains lost viability during testing (less than $8 \%$ from any source) and were discarded. A total of 276 isolates from incubation at $4{ }^{\circ} \mathrm{C}$ (designated $4{ }^{\circ} \mathrm{C}$ isolates) and 277 from incubation at $20^{\circ} \mathrm{C}$ (designated $20^{\circ} \mathrm{C}$ isolates) (Table 2) were used for the cluster analyses, together with 11 reference strains: Vibrio fischeri ATCC 15381, Pseudomonas coenobios ATCC 14402, Flavobacterium halmephilum ATCC 19717, Flavobacterium marinotypicum ATCC 19260, Alcaligenes pacificus atcc 27122, Pseudomonas doudoroffii atcc 27123, Pseudomonas marina atcc 27129, Pseudomonas nautica ATC: 27132, Arthrobacter citreus ATCC 11624, Ben sckea campbellii ATCC 25920 and Vibrio alginolyticus ATCC 17749. 
Table 2. Numbers and sources of isolates used in cluster analyses

\begin{tabular}{|c|c|c|c|c|}
\hline \multirow{2}{*}{$\begin{array}{c}\text { Station } \\
\text { (see Fig. 1) }\end{array}$} & \multicolumn{2}{|c|}{$4^{\circ} \mathrm{C}$ isolates } & \multicolumn{2}{|c|}{$20^{\circ} \mathrm{C}$ isolates } \\
\hline & Water & Sediment & Water & Sediment \\
\hline 1 & 4 & 5 & - & - \\
\hline 2 & 4 & 5 & - & — \\
\hline 2 & 24 & 24 & 24 & 24 \\
\hline 10 & 14 & 24 & 24 & 23 \\
\hline 30 & 2 & 24 & 24 & 24 \\
\hline 55 & $2 \overline{3}$ & 25 & 19 & 25 \\
\hline 70 & 25 & 25 & 20 & 25 \\
\hline 71 & 25 & 23 & 21 & 24 \\
\hline
\end{tabular}

Characterization of isolates. Approximately 300 phenotypic characteristics were determined for each strain (see Table 4). Unless otherwise indicated, tests on the $4{ }^{\circ} \mathrm{C}$ and $20^{\circ} \mathrm{C}$ isolates were incubated at $4{ }^{\circ} \mathrm{C}$ and $20^{\circ} \mathrm{C}$, respectively.

Morphology. Cultures ( 1 to $4 \mathrm{~d}$ depending on growth rate) from marine agar slants overlaid with $1 \mathrm{ml}$ Rila marine salts solution were examined for: cell shape, size and motility (wet mounts); spores, refractile granules of poly- $\beta$-hydroxybutyrate (Stanier et al., 1966) and capsules (India ink stain) (phase contrast microscopy); Gram reaction (Hucker modification), acid fastness (Ziehl-Neelsen method) and fat droplets (Burdon method) (Society of American Bacteriologists, 1957). Cultures (10 d) on marine agar were examined for colony morphology and size, and for production of diffusible and non-diffusible pigments. Fluorescent pigment formation on marine agar containing $0.15 \%(\mathrm{w} / \mathrm{v})$ glycerol was assessed daily with ultraviolet light $(\lambda 260 \mathrm{~nm})$. Following 10 to 15 min adaptation of the observer to the dark, bioluminescence was tested in the dark daily for $10 \mathrm{~d}$ [cultures grown on: Bacto-tryptone, $0.5 \%$; Eacto-yeast extract, $0.3 \% ; \mathrm{Na}_{2} \mathrm{HPO}_{4}$, $0.35 \% ; \mathrm{NH}_{4} \mathrm{NO}_{3}, 0.15 \%$; glycerol, $3.0 \%$; agar, $1.5 \%$ (all w/v); in $\frac{3}{4}$-strength Rila marine salts solution, pH 7.6].

Physiological and biochemical tests. Tests were read after $14 \mathrm{~d}$ incubation unless stated otherwise. Growth on replicate marine agar plates was tested at $5,10,15,20,25,37$ and $43{ }^{\circ} \mathrm{C}$, and at initial $\mathrm{pH} 3,4$, $5,6,7,8,9$ and 10 (adjusted with $\mathrm{HCl}$ or $\mathrm{NaOH}$ ). Salt tolerance and requirement were tested in the following medium without $\mathrm{NaCl}$ and with $0 \cdot 5,3,5,7 \cdot 5,10$ and $15 \%(\mathrm{w} / \mathrm{v}) \mathrm{NaCl}$ added: Bacto-tryptone, $0.5 \%$; Bactoyeast extract, $0.1 \% ; \mathrm{FeCl}_{3} .6 \mathrm{H}_{2} \mathrm{O}, 0.01 \% ; \mathrm{NH}_{4} \mathrm{NO}_{3}, 0.00016 \% ; \mathrm{Na}_{2} \mathrm{HFO}_{4}, 0.0008 \%$; Bacto-agar, $1.5 \%$ (all $\mathrm{w} / \mathrm{v}) ; \mathrm{pH} 8 \cdot 0$. Oxygen relations were determined from stab cultures in marine agar butts.

Distribution of growth, indole production (Kovacs method; Society of American Bacteriologists, 1957) and ammonia production (Nessler's reagent) were determined from $10 \mathrm{~d}$ cultures in a medium containing: Bacto-tryptone, $0.3 \%$; Bacto-yeast extract, $0.05 \%$; Tris, $0.6 \%$; $\mathrm{KH}_{2} \mathrm{PO}_{4}, 0.01 \% ; \mathrm{FeCl}_{3} .6 \mathrm{H}_{2} \mathrm{O}, 0.0005 \%$ (all $\mathrm{w} / \mathrm{v})$; thiamin, sodium pantothenate, riboflavin, nicotinic acid, choline, pyridoxamine and cyanocobalamin, all $1 \mu \mathrm{g} \mathrm{l}^{-1}$; folic acid, sodium $p$-aminobenzoate and biotin, all $0.05 \mu \mathrm{g} \mathrm{l}^{-1}$.

Cultures $(10 \mathrm{~d})$ on marine agar were tested for catalase (with $3 \% \mathrm{H}_{2} \mathrm{O}_{2}$ ) and cytochrome oxidase production (Gaby \& Hadley method, allowing 1 min for the blue colour to develop; Skerman, 1969). Methyl red and Voges-Proskauer tests (Society of American Bacteriologists, 1957) were done in MR-VP broth (Difco) prepared with full-strength Rila marine salts solution. Alkaline phosphatase was detected (Barber \& Kuper, $1951)$ in cultures $(10 \mathrm{~d})$ grown in a medium containing: Bacto-tryptone, $0.5 \%$; Bacto-yeast extract, $0.1 \%$; $\mathrm{NH}_{4} \mathrm{NO}_{3}, 0.00016 \% ; \mathrm{FeCl}_{3} .6 \mathrm{H}_{2} \mathrm{O}, 0.0005 \%$; phenolphthalein diphosphate, $0.001 \%$ (all w/v); in $\frac{3}{4}$-strength Rila marine salts solution, $\mathrm{pH} 7 \cdot 2$. Arginine, ornithine and lysine decarboxylases were detected by the Falkow method (Skerman, 1969), modified by replacing distilled water with Rila marine salts solution. These tests measure alkaline end-products and do not distinguish between arginine decarboxylase and arginine dihydrolase.

Nitrate and nitrite reduction were tested in nitrate broth (Difco) with full-strength Rila marine salts solution. Nitrite was detected with naphthylamine-sulphanilic acid reagent and residual nitrate with zinc dust (Skerman, 1969).

Acid production from D-ribose, D-fructose, cellobiose, lactose, sucrose or D-mannitol (all $1 \%$, w/v) was detected in MOF medium (Difco). Oxidation/fermentation tests were done in MOF medium containing $1 \%$ (w/v) D-glucose (Leifson, 1963). Gas production from glucose was detected with inverted Durham tubes in the liquid medium used for deternining growth distribution, supplemented with $1 \%(\mathrm{w} / \mathrm{v}) \mathrm{D}$-glucose. Substrates were filter-sterilized.

Agar hydrolysis was tested on marine agar; sunken colonies and depressions around colonies were scored as positive. Lipase activity was tested in marine agar containing $0.01 \%(\mathrm{w} / \mathrm{v}) \mathrm{CaCl}_{2}$ and $1 \%(\mathrm{w} / \mathrm{v})$ Tween 20 
or Tween 80 (Sierra, 1957). Starch hydrolysis was tested by flooding plate cultures (7 d) on marine agar containing $0.5 \%(\mathrm{w} / \mathrm{v})$ potato starch with Lugol's iodine. Gelatin hydrolysis was tested by flooding cultures ( 7 to $10 \mathrm{~d}$ ) on marine agar containing $10 \%$ (w/v) gelatin with acid $\mathrm{HgCl}_{2}$ (Skerman, 1969). Casein hydrolysis was tested on marine agar overlaid with a double layer of $10 \%(w / v)$ skim milk agar. For the last three tests, clear zones around colonies were recorded as positive.

Antibiotic sensitivity tests. Antibiotic sensitivity was tested by spreading bacterial suspensions on marine agar plates and applying BBL antibiotic discs (ampicillin, $2 \mu \mathrm{g}$; colistin, $10 \mu \mathrm{g}$; erythromycin, $15 \mu \mathrm{g}$; kanamycin, $30 \mu \mathrm{g}$; neomycin, $30 \mu \mathrm{g}$; nitrofurantoin, $300 \mu \mathrm{g}$; novobiocin, $5 \mu \mathrm{g}$; oxytetracycline, $5 \mu \mathrm{g}$; penicillin G, 2 units; polymyxin B, 300 units; streptomycin, $2 \mu \mathrm{g}$; tetracycline, $5 \mu \mathrm{g}$ ). Zones of inhibition were measured and sensitivity was determined against standard inhibition zones (BBL).

Nutritional tests. Basal medium $\mathrm{B}$ used in testing for substrate utilization was prepared as follows. Portion 1: $\mathrm{KH}_{2} \mathrm{PO}_{4}, 0.1 \mathrm{~g}$; Tris, $6.0 \mathrm{~g} ; \mathrm{NH}_{4} \mathrm{NO}_{3}, 1.0 \mathrm{~g}$; $\mathrm{FeCl}_{3} .6 \mathrm{H}_{2} \mathrm{O}, 0.005 \mathrm{~g}$; Rila marine salts solution, $500 \mathrm{ml}$; $\mathrm{pH}$ adjusted with $\mathrm{HCl}$ to $8 \cdot 0$. Portion 2: purified agar (Difco), $10 \mathrm{~g}$; distilled water, $500 \mathrm{ml}$. Portion 3: thiamin, sodium pantothenate, riboflavin, nicotinic acid, choline, pyridoxamine and cyanocobalamin, all $1 \mu \mathrm{g}$; folic acid, sodium $p$-aminobenzoate and biotin, all $0.05 \mu \mathrm{g}$; distilled water, $2 \mathrm{ml}$. Portions 1 and 2 were autoclaved separately. Portion 3 was filter-sterilized. The three portions were mixed at $55^{\circ} \mathrm{C}$. Substrates were sterilized by autoclaving or filtration (Stanier et al., 1966), except for hydrocarbons which were sterilized ultrasonically. Substrates were mixed with the basal medium just before pouring to give final concentrations of $0.1 \%(\mathrm{w} / \mathrm{v})$, except for carbohydrates $(0.15 \%, \mathrm{w} / \mathrm{v})$ and phenol $(0.0125 \%, \mathrm{w} / \mathrm{v})$. A total of 100 substrates was tested (most are listed in Table 4). To determine growth factor requirements, two additional basal media were used. Basal medium A was basal medium B without vitamins (portion 3). Basal medium E was basal medium B supplemented with $50 \mathrm{mg}$ Bacto-yeast extract, $50 \mathrm{mg}$ Casamino acids and $10 \mathrm{mg}$ L-tryptophan. Twelve substrates (D-ribose, D-fructose, D-glucose, acetate, succinate, fumarate, DL- $\beta$-hydroxybutyrate, DL-lactate, pyruvate, 2-ketoglutarate, D-gluconate, glycerol) were used to test the ability of strains to grow on the basal media. Four classes of growth factor requirements were tested: type 1, bacteria able to grow on all basal media (do not require growth factors); type 2, bacteria able to grow on basal media $B$ and $\mathrm{E}$ but not $\mathrm{A}$ (require vitamins as growth factors); type 3, bacteria able to grow on basal medium $\mathrm{E}$ but not $\mathrm{A}$ or B (require complex growth factors such as amino acids); type 4, bacteria unable to grow on any basal medium (require complex unknown growth factors).

Plates were inoculated with a multiple syringe inoculator (Kaneko et al., 1977a). Growth with any substrate was considered positive if within $14 \mathrm{~d}$ it exceeded (visually) that on the same basal medium alone.

Data processing and analysis. Data were coded in binary form according to RKC format (Rogosa et al., 1971), punched on cards, and verified and proof-read by two people. Errors were also checked by computer with the CREATE program (Krichevsky, 1977). Test reproducibility was checked by periodically retesting selected strains. The estimated total error rate was less than $3 \%$, which would not significantly affect the cluster analyses. The QUERY computer program (Krichevsky, 1977) was used to arrange the data for input to the numerical taxonomy program GTP2 (supplied by R. R. Colwell). Editing removed strains lacking more than $35 \%$ data, and non- differentiating features with more than $99 \%$ positive, $99 \%$ negative or $90 \%$ missing results (MTRXED program; Walczak \& Krichevsky, 1977). Similarities were estimated with the Jaccard coefficient $\left(S_{J}\right)$ and cluster analyses were done by single linkage sorting (Sokal \& Sneath, 1963). Clusters of strains with similarities greater than $75 \%$ were designated as taxonomic groupings (Liston $e t$ al., 1963). The input data were sorted into the same order as strains in the cluster analysis triangle. The feature frequencies of all characteristics were determined with the feature analysis program FREAK (Walczak et al., 1978). Probabalistic identifications were attempted using the program IDDNEW and three identification matrices currently being developed at the American Type Culture Collection ( $\mathrm{R}$. Johnson, unpublished).

\section{RESULTS}

\section{General characteristics}

Table 3 summarizes the occurrence of selected features in the bacterial populations. Gram-negative rods predominated in water and sediment. The majority of $4{ }^{\circ} \mathrm{C}$ isolates from water were orange. Of the $20^{\circ} \mathrm{C}$ isolates, more from sediment than from water were pigmented. The $20^{\circ} \mathrm{C}$ isolates grew at higher temperatures and salinities than did the $4{ }^{\circ} \mathrm{C}$ isolates. More sediment than water isolates tolerated low $\mathrm{pH}$. Most isolates grew at 5 to $15^{\circ} \mathrm{C}, \mathrm{pH} 6$ to 8 and salinities of $3 \%(\mathrm{w} / \mathrm{v}) \mathrm{NaCl}$.

More sediment than water isolates hydrolysed starch and gelatin. The $20^{\circ} \mathrm{C}$ isolates from water and sediment were equally lipolytic, but more $4{ }^{\circ} \mathrm{C}$ sediment isolates than water isolates were lipolytic. Nitrate reduction was common in $4{ }^{\circ} \mathrm{C}$ sediment isolates but rare in $4{ }^{\circ} \mathrm{C}$ water isolates. Almost equal numbers of $20^{\circ} \mathrm{C}$ isolates reduced nitrate. Few strains 
Table 3. Occurrence of selected features in water and sediment bacterial populations isolated at 4 and $20^{\circ} \mathrm{C}$ (expressed as a percentage of the total scored in each group for the given test)

\begin{tabular}{|c|c|c|c|c|}
\hline \multirow[b]{2}{*}{ Feature } & \multicolumn{2}{|c|}{$4^{\circ} \mathrm{C}$ isolates } & \multicolumn{2}{|c|}{$20^{\circ} \mathrm{C}$ isolates } \\
\hline & Water & Sediment & Water & Sediment \\
\hline Rod-shaped & 100 & 100 & 98 & 99 \\
\hline Curved axis & 29 & 56 & 13 & 34 \\
\hline Gram-negative & 99 & 99 & 94 & 97 \\
\hline Motile & 4 & 48 & 5 & 5 \\
\hline Capsule & 19 & 26 & 8 & 18 \\
\hline \multicolumn{5}{|l|}{ Length } \\
\hline $1 \cdot 1-2 \cdot 0 \mu \mathrm{m}$ & 29 & 10 & 33 & 19 \\
\hline $2 \cdot 1-3 \cdot 0 \mu \mathrm{m}$ & 40 & 30 & 26 & 27 \\
\hline $3 \cdot 1-4 \cdot 0 \mu \mathrm{m}$ & 18 & 40 & 17 & 27 \\
\hline Non-pigmented & 23 & 56 & 65 & 32 \\
\hline Orange & 67 & 23 & 11 & 30 \\
\hline Yellow & 5 & 10 & 21 & 33 \\
\hline \multicolumn{5}{|l|}{ Growth at: } \\
\hline $5^{\circ} \mathrm{C}$ & 100 & 100 & 98 & 97 \\
\hline $10^{\circ} \mathrm{C}$ & 100 & 99 & 98 & 99 \\
\hline $15^{\circ} \mathrm{C}$ & 98 & 99 & 99 & 99 \\
\hline $20^{\circ} \mathrm{C}$ & 82 & 56 & 98 & 99 \\
\hline $25^{\circ} \mathrm{C}$ & 18 & 20 & 89 & 77 \\
\hline $37{ }^{\circ} \mathrm{C}$ & 1 & 0 & 7 & 4 \\
\hline pH 5 & 52 & 82 & 53 & 74 \\
\hline pH 6 & 90 & 96 & 98 & 100 \\
\hline $\mathrm{pH} 7$ & 98 & 97 & 98 & 99 \\
\hline pH 8 & 89 & 96 & 98 & 99 \\
\hline pH 9 & 73 & 84 & 87 & 46 \\
\hline $0 \%(\mathrm{w} / \mathrm{v}) \mathrm{NaCl}$ & 8 & 16 & 37 & 32 \\
\hline $0.5 \%(\mathrm{w} / \mathrm{v}) \mathrm{NaCl}$ & 8 & 52 & 94 & 82 \\
\hline $3 \%(\mathrm{w} / \mathrm{v}) \mathrm{NaCl}$ & 92 & 93 & 97 & 99 \\
\hline $5 \%(\mathrm{w} / \mathrm{v}) \mathrm{NaCl}$ & 72 & 69 & 92 & 63 \\
\hline $7.5 \%(\mathrm{w} / \mathrm{v}) \mathrm{NaCl}$ & 27 & 20 & 63 & 48 \\
\hline $10 \%$ (w/v) $\mathrm{NaCl}$ & 17 & 17 & 53 & 46 \\
\hline Starch hydrolysis & 9 & 36 & 17 & 55 \\
\hline Gelatin hydrolysis & 41 & 50 & 18 & 43 \\
\hline Tween 20 hydrolysis & 14 & 62 & 51 & 48 \\
\hline Tween 80 hydrolysis & 20 & 62 & 79 & 74 \\
\hline Phosphatase & 88 & 86 & 69 & 79 \\
\hline Catalase & 90 & 72 & 70 & 77 \\
\hline Oxidase & 0 & 16 & 4 & 8 \\
\hline Arginine decarboxylase & 63 & 42 & 16 & 16 \\
\hline Lysine decarboxylase & 18 & 19 & 5 & 6 \\
\hline Ornithine decarboxylase & 5 & 10 & 9 & 19 \\
\hline Ammonia from peptone & 9 & 37 & 36 & 69 \\
\hline Nitrate to nitrite & 3 & 64 & 27 & 22 \\
\hline \multicolumn{5}{|l|}{ Acid from: } \\
\hline Glucose (oxid.) & 24 & 62 & 13 & 38 \\
\hline Glucose (ferm.) & 30 & 60 & 49 & 50 \\
\hline Lactose & 5 & 5 & 8 & 12 \\
\hline Sucrose & 44 & 18 & 43 & 36 \\
\hline \multicolumn{5}{|l|}{ Utilization of: } \\
\hline Carbohydrates & 55 & 67 & 90 & 44 \\
\hline Glucose & 58 & 50 & 85 & 31 \\
\hline Organic acids & 37 & 69 & 88 & 50 \\
\hline Acetate & 20 & 17 & 78 & 27 \\
\hline Pyruvate & 30 & 50 & 76 & 38 \\
\hline Alcohols & 29 & 56 & 79 & 31 \\
\hline Glycerol & 28 & 35 & 66 & 25 \\
\hline Amino acids & 32 & 40 & 83 & 37 \\
\hline Hydrocarbons & 0 & 0 & 6 & 6 \\
\hline \multicolumn{5}{|l|}{ Growth factor: } \\
\hline Type 1 & 4 & 24 & 17 & 14 \\
\hline Type 2 & 66 & 53 & 73 & 38 \\
\hline Type 3 & 25 & 18 & 6 & 37 \\
\hline Type 4 & 5 & 5 & 4 & 10 \\
\hline
\end{tabular}



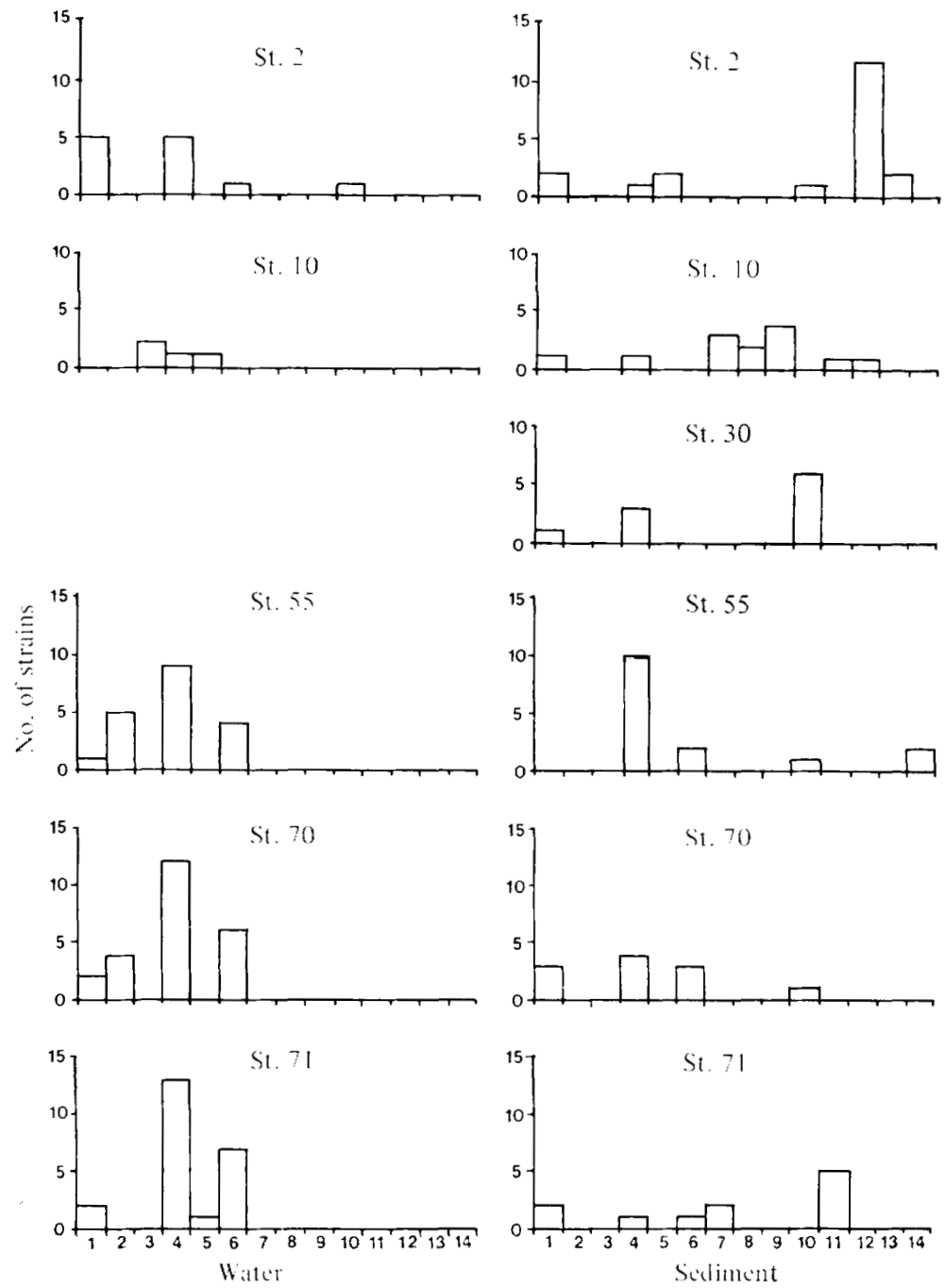

(Cluster no. (L series)

Fig. 2. Distribution of phenotypic clusters of $4{ }^{\circ} \mathrm{C}$ isolates. The positions of the sampling stations are indicated in Fig. 1.

were oxidase-positive. Isolates utilizing at least one substrate were counted for each class of substrates. The frequencies of utilization were in the order: carbohydrates $>$ carboxylic acids $>$ amino acids $>$ alcohols $\gg$ hydrocarbons. The $4{ }^{\circ} \mathrm{C}$ sediment isolates utilized more substrates than did the $4{ }^{\circ} \mathrm{C}$ water isolates; the reverse was true for $20^{\circ} \mathrm{C}$ isolates. Since substrate utilization was determined with only vitamins as growth factors, fastidious organisms (growth factor requirement type 3 or 4 ) were not tested. Thus, only $70 \%$ of $4{ }^{\circ} \mathrm{C}$ water isolates, $77 \%$ of $4{ }^{\circ} \mathrm{C}$ sediment isolates, $90 \%$ of $20{ }^{\circ} \mathrm{C}$ water isolates and $52 \%$ of $20^{\circ} \mathrm{C}$ sediment isolates could be tested. Obviously, growth factors are extremely important nutritional requirements for the Beaufort Sea bacteria.

\section{Cluster analyses}

Of the $4{ }^{\circ} \mathrm{C}$ isolates (L series), $62 \%$ fell into 14 clusters at the $75 \%$ similarity level. Four of these clusters had only two members. The remaining $38 \%$ of the $4{ }^{\circ} \mathrm{C}$ isolates did not cluster at this similarity level. The largest cluster (L4), tentatively identified as Flavobac- 

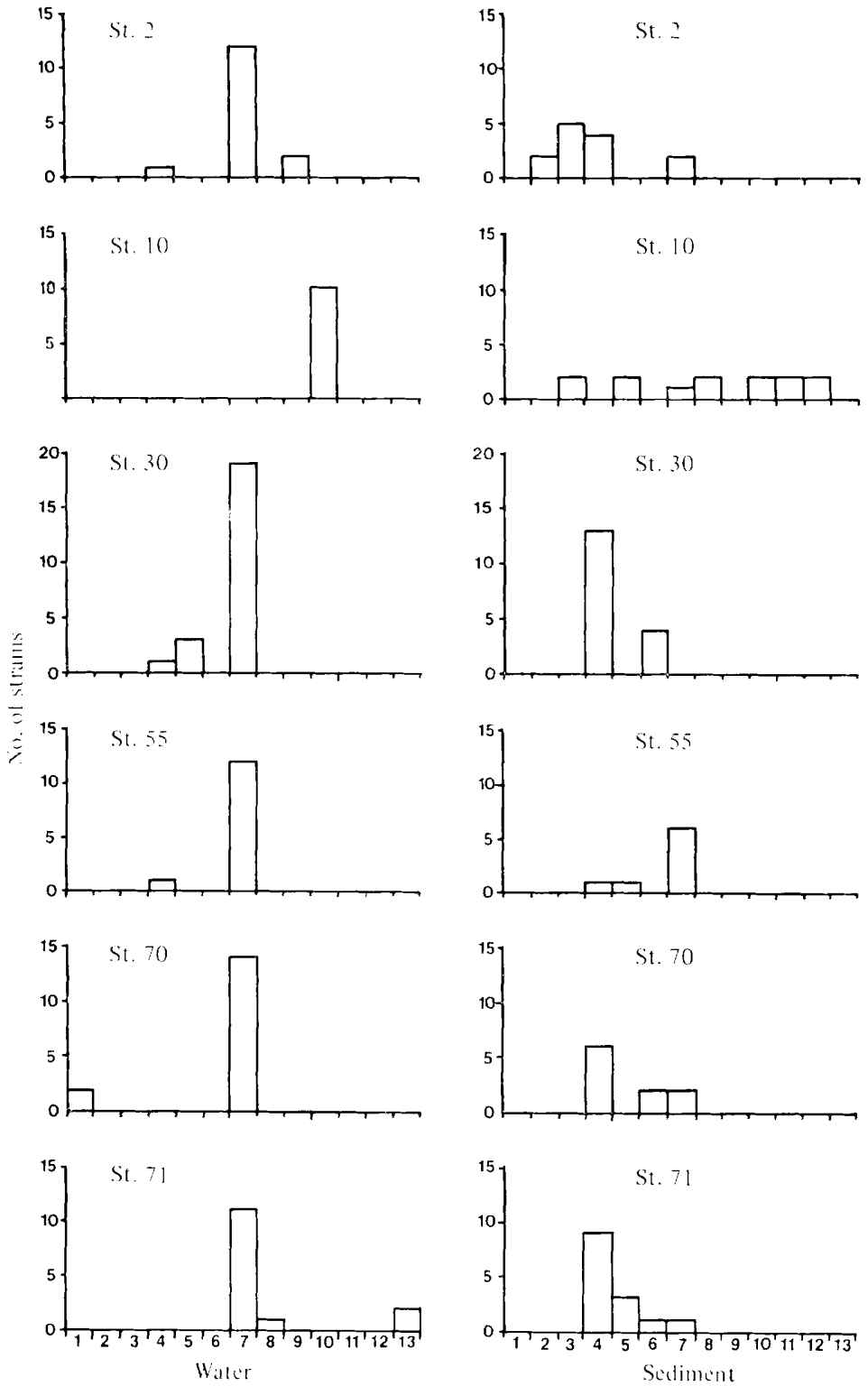

(Huiler mo. II seriess

Fig. 3. Distribution of phenotypic clusters of $20^{\circ} \mathrm{C}$ isolates.

The positions of the sampling stations are indicated in Fig. 1.

terium, had 60 strains (accounting for $20 \%$ of the total $4{ }^{\circ} \mathrm{C}$ isolates) of which $67 \%$ were isolated from water (Fig. 2). The second largest cluster (L6), also tentatively identified as Flavobacterium, contained 28 strains, $80 \%$ of which were isolated from water.

The $20{ }^{\circ} \mathrm{C}$ isolates (H series) fell into 13 clusters, which contained $60 \%$ of the isolates. Six clusters had only two members. The overall populations were very diverse (Kaneko et al., 1977b). In the largest cluster (H7), which has not been identified, $85 \%$ of the strains were isolated from water and accounted for $52 \%$ of all $20{ }^{\circ} \mathrm{C}$ water isolates (Fig. 3). The second largest cluster (H4), tentatively identified as Flavobacterium, contained $13 \%$ of all $20^{\circ} \mathrm{C}$ isolates. 


\section{Table 4. Feature frequencies* of selected characteristics of major clusters of bacterial populations isolated at 4 and $20{ }^{\circ} \mathrm{C}$}

Cluster

No. of strains

Cell morphology

Rod-shaped

Curved axis

Coccobacillary

Pear-shaped

Pleomorphic

Tapered end

Rounded end

Cell length

$0 \cdot 5-1 \cdot 0 \mu \mathrm{m}$

$1 \cdot 1-2 \cdot 0 \mu \mathrm{m}$

$3 \cdot 1-4 \cdot 0 \mu \mathrm{m}$

$4 \cdot 1-5 \cdot 0 \mu \mathrm{m}$

$5 \cdot 1-10 \cdot 0 \mu \mathrm{m}$

Cell width

$<0.5 \mu \mathrm{m}$

$0.5-1 \cdot 0 \mu \mathrm{m}$

$1 \cdot 1-2 \cdot 0 \mu \mathrm{m}$
$2 \cdot 1-3 \cdot 0 \mu \mathrm{m}$

$\begin{array}{lllllllllllllllllllll}\text { L1 } & \text { L2 } & \text { L4 } & \text { L5 } & \text { L6 } & \text { L7 } & \text { L9 } & \text { L10 L11 L12 H3 } & \text { H4 } & \text { H5 } & \text { H6 } & \text { H7 } & \text { H8 } & \text { H10 }\end{array}$

$\begin{array}{lllllllllllllllll}21 & 9 & 60 & 4 & 28 & 7 & 4 & 10 & 6 & 13 & 7 & 36 & 9 & 7 & 80 & 3 & 12\end{array}$

$\begin{array}{lllllllllllllllll}100 & 100 & 100 & 100 & 100 & 100 & 100 & 100 & 100 & 100 & 100 & 100 & 88 & 100 & 100 & 100 & 100\end{array}$ $\begin{array}{rrrrrrrrrrrrrrrrr}28 & 44 & 11 & 100 & 32 & 71 & 25 & 70 & 100 & 84 & 0 & 88 & 33 & 57 & 6 & 0 & 25\end{array}$

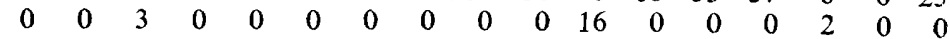
$\begin{array}{lllllllllllllllll}14 & 88 & 15 & 25 & 21 & 0 & 0 & 20 & 25 & 15 & 0 & 2 & 0 & 28 & 38 & 33 & 0\end{array}$ $\begin{array}{lllllllllllllllll}95 & 77 & 96 & 100 & 96 & 85 & 100 & 88 & 100 & 92 & 33 & 85 & 55 & 42 & 38 & 66 & 83\end{array}$

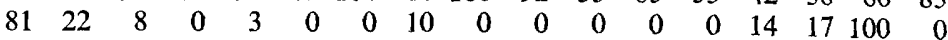
$\begin{array}{lllllllllllllllll}100 & 100 & 100 & 100 & 100 & 100 & 100 & 100 & 100 & 100 & 100 & 100 & 100 & 100 & 97 & 100 & 91\end{array}$

$$
\begin{array}{rrrrrrrrrrrrrrrrr}
0 & 0 & 1 & 0 & 3 & 0 & 0 & 0 & 0 & 0 & 66 & 0 & 0 & 14 & 7 & 0 & 0 \\
0 & 33 & 42 & 0 & 29 & 16 & 0 & 20 & 0 & 0 & 0 & 2 & 55 & 28 & 42 & 0 & 8 \\
4 & 44 & 44 & 25 & 42 & 50 & 0 & 50 & 25 & 15 & 0 & 26 & 33 & 14 & 26 & 0 & 0 \\
4 & 22 & 10 & 50 & 17 & 33 & 25 & 30 & 75 & 69 & 16 & 45 & 11 & 0 & 10 & 100 & 50 \\
28 & 0 & 0 & 0 & 3 & 20 & 75 & 0 & 0 & 16 & 16 & 25 & 0 & 0 & 6 & 0 & 25 \\
65 & 0 & 1 & 25 & 0 & 0 & 0 & 0 & 0 & 0 & 0 & 0 & 0 & 42 & 6 & 0 & 16
\end{array}
$$

Cell arrangement

Presence of single cells 100100100100100100100100100100100100100100100100100 Chain formation Irregular aggregates

$\begin{array}{lllllllllllllllll}0 & 0 & 10 & 50 & 39 & 0 & 0 & 0 & 0 & 0 & 66 & 8 & 44 & 14 & 6 & 0 & 0\end{array}$ $\begin{array}{lllllllllllllllll}81 & 100 & 89 & 50 & 60 & 100 & 100 & 100 & 100 & 84 & 33 & 91 & 66 & 85 & 93 & 100 & 100\end{array}$

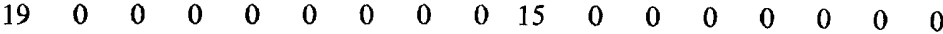

$\begin{array}{rrrrrrrrrrrrrrrrr}5 & 33 & 63 & 0 & 67 & 0 & 25 & 50 & 0 & 0 & 0 & 0 & 33 & 14 & 8 & 33 & 41\end{array}$

Miscellaneous cell features

Capsule

Acid fast

Sudan black

Gram-negative

Motile

Colony pigment

Non-diffusible yellow

Non-diffusible orange

White

Grey

Colony size

$<1 \mathrm{~mm}$

1-2 mm

2-6 mm

Colony morphology

Translucent

Transparent

Opaque

Entire

Convex

Mucoid

Glistening

Smooth

Growth in liquid media

No growth in liquid

Floccular

Ring

Pellicle

Even

Slight or no turbidity

Moderate turbidity

Heavy turbidity

$\begin{array}{lllllllllllllllll}81 & 55 & 0 & 0 & 0 & 0 & 0 & 0 & 0 & 0 & 0 & 0 & 0 & 14 & 12 & 100 & 8\end{array}$

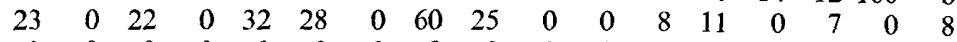
$\begin{array}{lllllllllllllllll}0 & 0 & 0 & 0 & 0 & 0 & 0 & 0 & 0 & 0 & 0 & 0 & 0 & 0 & 0 & 0 & 0\end{array}$ $\begin{array}{lllllllllllllllll}95 & 77 & 3 & 0 & 3 & 0 & 0 & 0 & 0 & 0 & 0 & 2 & 0 & 28 & 30 & 100 & 0\end{array}$

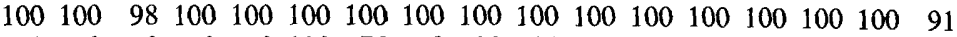

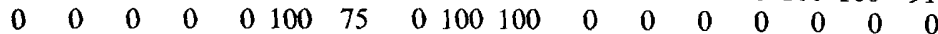

$\begin{array}{lllllllllllllllll}0 & 0 & 3 & 66 & 3 & 0 & 0 & 0 & 25 & 0 & 83 & 11 & 88 & 0 & 0 & 0 & 100\end{array}$ $\begin{array}{lllllllllllllllll}4 & 22 & 95 & 33 & 92 & 0 & 0 & 10 & 0 & 0 & 16 & 68 & 11 & 0 & 0 & 0 & 0\end{array}$ $\begin{array}{rrrrrrrrrrrrrrrrr}0 & 0 & 0 & 0 & 0 & 0 & 0 & 0 & 0 & 7 & 0 & 0 & 0 & 14 & 3 & 0 & 0\end{array}$ $\begin{array}{lllllllllllllllll}95 & 77 & 0 & 0 & 3 & 100 & 100 & 80 & 75 & 92 & 0 & 22 & 0 & 85 & 97 & 100 & 0\end{array}$

$\begin{array}{lllllllllllllllll}100 & 88 & 100 & 100 & 85 & 0 & 25 & 100 & 0 & 15 & 83 & 45 & 100 & 85 & 43 & 66 & 100\end{array}$ $\begin{array}{lllllllllllllllll}0 & 0 & 0 & 0 & 0 & 14 & 75 & 0 & 25 & 61 & 16 & 54 & 0 & 14 & 48 & 33 & 0\end{array}$ $\begin{array}{rrrrrrrrrrrrrrrrr}0 & 0 & 0 & 0 & 0 & 85 & 0 & 0 & 75 & 23 & 0 & 0 & 0 & 0 & 7 & 0 & 0\end{array}$

$\begin{array}{lllllllllllllllll}66 & 77 & 96 & 66 & 89 & 0 & 100 & 90 & 25 & 7 & 33 & 74 & 100 & 85 & 47 & 0 & 16\end{array}$ $\begin{array}{rrrrrrrrrrrrrrrrr}23 & 22 & 3 & 33 & 10 & 14 & 0 & 10 & 0 & 0 & 0 & 22 & 0 & 14 & 2 & 33 & 0\end{array}$ $\begin{array}{rrrrrrrrrrrrrrrrr}9 & 0 & 0 & 0 & 0 & 85 & 0 & 0 & 75 & 92 & 66 & 5 & 0 & 0 & 50 & 100 & 83\end{array}$ $\begin{array}{lllllllllllllllll}95 & 100 & 100 & 100 & 89 & 100 & 100 & 100 & 100 & 100 & 100 & 100 & 100 & 100 & 98 & 66 & 100\end{array}$ $\begin{array}{lllllllllllllllll}100 & 88 & 96 & 100 & 100 & 100 & 50 & 100 & 75 & 92 & 100 & 85 & 100 & 85 & 79 & 100 & 100\end{array}$ $\begin{array}{lllllllllllllllll}0 & 0 & 0 & 0 & 0 & 42 & 25 & 20 & 0 & 0 & 16 & 2 & 0 & 28 & 1 & 0 & 0\end{array}$ $\begin{array}{lllllllllllllllll}100 & 100 & 100 & 100 & 100 & 100 & 100 & 100 & 100 & 100 & 83 & 100 & 100 & 100 & 86 & 33 & 75\end{array}$

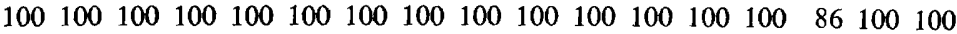

$\begin{array}{rrrrrrrrrrrrrrrrr}4 & 33 & 5 & 33 & 7 & 0 & 0 & 0 & 0 & 0 & 0 & 0 & 0 & 0 & 0 & 0 & 0 \\ 10 & 0 & 0 & 0 & 4 & 16 & 100 & 0 & 50 & 0 & 75 & 5 & 33 & 0 & 19 & 33 & 27 \\ 0 & 0 & 3 & 0 & 0 & 0 & 0 & 0 & 25 & 30 & 0 & 37 & 77 & 42 & 0 & 0 & 0 \\ 5 & 0 & 1 & 0 & 0 & 83 & 100 & 0 & 50 & 0 & 0 & 2 & 0 & 14 & 3 & 0 & 0 \\ 47 & 16 & 35 & 0 & 28 & 33 & 100 & 100 & 75 & 100 & 25 & 94 & 88 & 100 & 27 & 66 & 36 \\ 68 & 100 & 75 & 100 & 92 & 33 & 0 & 20 & 0 & 0 & 75 & 31 & 0 & 42 & 73 & 100 & 90 \\ 26 & 0 & 24 & 0 & 12 & 50 & 100 & 80 & 100 & 100 & 25 & 68 & 66 & 57 & 26 & 0 & 9 \\ 5 & 0 & 0 & 0 & 0 & 16 & 0 & 0 & 0 & 0 & 0 & 0 & 33 & 0 & 0 & 0 & 0\end{array}$


Table 4. (cont.)

Cluster

No. of strains

Acid from

D-Ribose

D-Fructose

Cellobiose

Lactose

Sucrose

D-Mannitol

D-Glucose (aerobic)

D-Glucose (ferm.)

Miscellaneous features

Indole produced

Ammonia produced

Nitrate reduced

Nitrite reduced

Arginine decarboxylase

Lysine decarboxylase

Ornithine decarboxylase 12

Gelatin hydrolysis

Starch hydrolysis

Tween 20 hydrolysis

Tween 80 hydrolysis

Catalase

Oxidase

Alkaline phosphatase

Urease

$\mathrm{pH}$ : growth at

pH 4

pH 5

pH 6

pH 7

pH 8

pH 9

pH 10

Temperature: growth at

$5{ }^{\circ} \mathrm{C}$

$10{ }^{\circ} \mathrm{C}$

$15^{\circ} \mathrm{C}$

$20^{\circ} \mathrm{C}$

$25^{\circ} \mathrm{C}$

$37^{\circ} \mathrm{C}$

$43{ }^{\circ} \mathrm{C}$

$\mathrm{NaCl}$ : growth at

$0 \%(\mathrm{w} / \mathrm{v})$

$0.5 \%(\mathrm{w} / \mathrm{v})$

$3 \%(w / v)$

$5 \%(\mathrm{w} / \mathrm{v})$

$7.5 \%(\mathrm{w} / \mathrm{v})$

$10 \%(\mathrm{w} / \mathrm{v})$

$15 \%(\mathrm{w} / \mathrm{v})$

Carbohydrates utilized

L-Arabinose

D-Ribose

D-Xylose

D-Fructose

D-Galactose

D-Glucose

D-Mannose

L-Sorbose

Salicin

Cellobiose

Lactose

Maltose

Sucrose

Trehalose

Raffinose

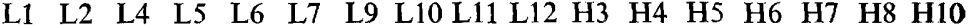
$\begin{array}{lllllllllllllllll}21 & 9 & 60 & 4 & 28 & 7 & 4 & 10 & 6 & 13 & 7 & 36 & 9 & 7 & 80 & 3 & 12\end{array}$

$\begin{array}{lllllllllllllllll}0 & 0 & 2 & 0 & 0 & 0 & 0 & 0 & 100 & 81 & 0 & 9 & 0 & 14 & 35 & 0 & 0\end{array}$

$\begin{array}{lllllllllllllllll}0 & 16 & 32 & 0 & 13 & 0 & 0 & 0 & 100 & 84 & 0 & 9 & 0 & 14 & 27 & 0 & 0\end{array}$

$\begin{array}{lllllllllllllllll}0 & 0 & 0 & 0 & 0 & 14 & 0 & 0 & 0 & 7 & 0 & 2 & 0 & 14 & 2 & 0 & 8\end{array}$

$\begin{array}{lllllllllllllllll}0 & 0 & 0 & 0 & 0 & 0 & 0 & 0 & 0 & 0 & 0 & 5 & 0 & 0 & 3 & 0 & 0\end{array}$

$\begin{array}{lllllllllllllllll}0 & 14 & 57 & 0 & 50 & 0 & 0 & 11 & 0 & 0 & 0 & 68 & 0 & 0 & 48 & 0 & 8\end{array}$

$\begin{array}{lllllllllllllllll}0 & 0 & 0 & 0 & 0 & 0 & 0 & 0 & 25 & 0 & 0 & 20 & 0 & 14 & 6 & 0 & 0\end{array}$

$\begin{array}{rrrrrrrrrrrrrrrrr}26 & 0 & 15 & 0 & 60 & 50 & 100 & 0 & 100 & 100 & 0 & 52 & 11 & 16 & 9 & 0 & 9\end{array}$

$\begin{array}{lllllllllllllllll}26 & 12 & 20 & 0 & 27 & 75 & 100 & 0 & 100 & 100 & 16 & 69 & 33 & 0 & 59 & 33 & 0\end{array}$

$\begin{array}{lllllllllllllllll}0 & 0 & 0 & 0 & 0 & 0 & 0 & 0 & 0 & 7 & 0 & 0 & 0 & 0 & 0 & 0 & 0\end{array}$

$\begin{array}{lllllllllllllllll}6 & 0 & 3 & 0 & 3 & 14 & 100 & 0 & 75 & 100 & 0 & 85 & 88 & 85 & 12 & 33 & 0\end{array}$

$\begin{array}{lllllllllllllllll}0 & 0 & 0 & 0 & 0 & 100 & 100 & 100 & 100 & 100 & 83 & 11 & 0 & 85 & 3 & 33 & 100\end{array}$

$\begin{array}{lllllllllllllllll}0 & 0 & 0 & 0 & 0 & 42 & 0 & 37 & 0 & 0 & 0 & 5 & 0 & 0 & 1 & 0 & 0\end{array}$

$\begin{array}{rrrrrrrrrrrrrrrrr}56 & 71 & 70 & 66 & 65 & 14 & 0 & 40 & 50 & 23 & 50 & 29 & 22 & 33 & 15 & 0 & 0\end{array}$

$\begin{array}{lllllllllllllllll}28 & 0 & 16 & 0 & 16 & 0 & 0 & 44 & 0 & 53 & 0 & 0 & 12 & 0 & 3 & 50 & 0\end{array}$

$\begin{array}{rrrrrrrrrrrrrrrrr}12 & 0 & 2 & 50 & 0 & 28 & 50 & 12 & 0 & 0 & 0 & 21 & 25 & 14 & 9 & 50 & 0\end{array}$

$\begin{array}{lllllllllllllllll}14 & 22 & 55 & 0 & 42 & 85 & 100 & 20 & 50 & 38 & 0 & 64 & 0 & 14 & 3 & 0 & 0\end{array}$

$\begin{array}{rrrrrrrrrrrrrrrrr}0 & 0 & 5 & 0 & 0 & 85 & 0 & 0 & 75 & 100 & 100 & 83 & 11 & 0 & 0 & 0 & 100\end{array}$

$\begin{array}{lllllllllllllllll}12 & 33 & 1 & 0 & 21 & 100 & 100 & 100 & 100 & 100 & 28 & 18 & 100 & 100 & 45 & 66 & 50\end{array}$

$\begin{array}{lllllllllllllllll}40 & 75 & 11 & 25 & 11 & 100 & 100 & 50 & 0 & 100 & 0 & 91 & 88 & 42 & 82 & 100 & 90\end{array}$

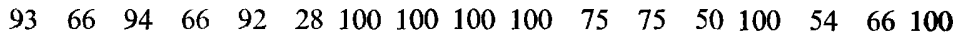

$\begin{array}{lllllllllllllllll}0 & 0 & 0 & 0 & 0 & 28 & 0 & 20 & 0 & 9 & 0 & 0 & 50 & 0 & 0 & 0 & 0\end{array}$

$\begin{array}{lllllllllllllllll}100 & 100 & 100 & 100 & 100 & 100 & 100 & 55 & 100 & 76 & 83 & 85 & 66 & 71 & 93 & 66 & 16\end{array}$

$\begin{array}{lllllllllllllllll}0 & 0 & 0 & 0 & 0 & 0 & 0 & 0 & 0 & 0 & 0 & 2 & 0 & 0 & 0 & 0 & 0\end{array}$

$\begin{array}{lllllllllllllllll}0 & 0 & 0 & 0 & 0 & 0 & 0 & 0 & 0 & 0 & 0 & 0 & 0 & 0 & 1 & 0 & 83\end{array}$

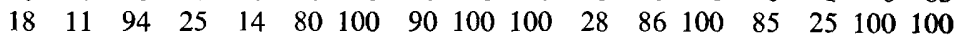
$\begin{array}{lllllllllllllllll}56 & 100 & 100 & 100 & 71 & 100 & 100 & 100 & 100 & 100 & 100 & 100 & 100 & 100 & 100 & 100 & 100\end{array}$ $\begin{array}{lllllllllllllllll}100 & 100 & 100 & 100 & 82 & 100 & 100 & 100 & 100 & 100 & 85 & 100 & 100 & 100 & 98 & 100 & 100\end{array}$ $\begin{array}{lllllllllllllllll}100 & 100 & 100 & 100 & 78 & 100 & 100 & 100 & 100 & 100 & 100 & 100 & 100 & 100 & 100 & 100 & 100\end{array}$ $\begin{array}{lllllllllllllllll}57 & 100 & 100 & 100 & 17 & 85 & 100 & 100 & 100 & 100 & 0 & 2 & 77 & 100 & 97 & 100 & 100\end{array}$ $\begin{array}{lllllllllllllllll}4 & 0 & 0 & 0 & 0 & 71 & 0 & 0 & 100 & 100 & 0 & 0 & 0 & 0 & 1 & 0 & 0\end{array}$

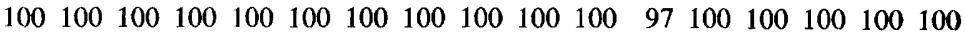

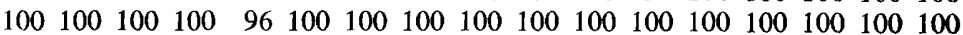
$\begin{array}{llllllllllllllllll}100 & 100 & 100 & 100 & 96 & 71 & 100 & 100 & 100 & 100 & 100 & 100 & 100 & 100 & 100 & 100 & 100\end{array}$ $\begin{array}{lllllllllllllllll}95 & 100 & 96 & 0 & 89 & 0 & 0 & 100 & 0 & 0 & 100 & 100 & 100 & 100 & 100 & 100 & 100\end{array}$

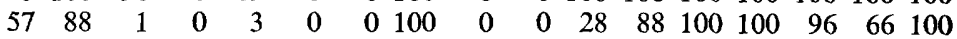
$\begin{array}{rrrrrrrrrrrrrrrrr}0 & 0 & 0 & 0 & 0 & 0 & 0 & 0 & 0 & 0 & 0 & 2 & 0 & 0 & 1 & 0 & 25 \\ 0 & 0 & 0 & 0 & 0 & 0 & 0 & 0 & 0 & 0 & 0 & 0 & 0 & 0 & 1 & 0 & 0\end{array}$

$\begin{array}{lllllllllllllllll}5 & 29 & 6 & 0 & 4 & 0 & 0 & 89 & 0 & 0 & 0 & 9 & 89 & 86 & 20 & 34 & 100\end{array}$

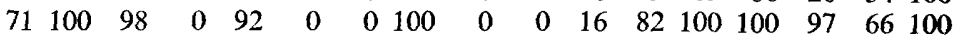
$\begin{array}{lllllllllllllllll}95 & 100 & 100 & 100 & 42 & 100 & 100 & 90 & 100 & 100 & 100 & 100 & 100 & 100 & 98 & 66 & 100\end{array}$ $\begin{array}{lllllllllllllllll}66 & 100 & 100 & 100 & 17 & 85 & 100 & 10 & 100 & 46 & 28 & 77 & 100 & 0 & 98 & 100 & 100\end{array}$ $\begin{array}{lllllllllllllllll}23 & 33 & 53 & 0 & 3 & 14 & 0 & 0 & 25 & 7 & 0 & 25 & 77 & 0 & 73 & 66 & 50\end{array}$ $\begin{array}{rllllllllllllllll}23 & 14 & 18 & 0 & 12 & 0 & 0 & 0 & 0 & 0 & 0 & 42 & 100 & 14 & 62 & 33 & 8\end{array}$

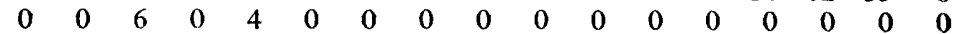

$\begin{array}{lllllllllllllllll}4 & 0 & 8 & 0 & 0 & 0 & 0 & 0 & 0 & 15 & 0 & 0 & 0 & 0 & 5 & 0 & 83\end{array}$

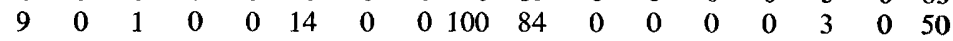
$\begin{array}{rrrrrrrrrrrrrrrrr}33 & 88 & 8 & 0 & 7 & 0 & 0 & 0 & 0 & 0 & 0 & 0 & 0 & 0 & 80 & 0 & 75\end{array}$ $\begin{array}{rllllllllllllllll}4 & 66 & 45 & 0 & 0 & 0 & 0 & 0 & 100 & 100 & 0 & 0 & 0 & 0 & 58 & 33 & 100\end{array}$ $\begin{array}{rrrrrrrrrrrrrrrrr}4 & 66 & 78 & 0 & 3 & 0 & 0 & 0 & 0 & 100 & 0 & 0 & 0 & 0 & 59 & 0 & 33\end{array}$

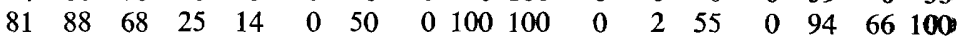
$\begin{array}{lllllllllllllllll}0 & 0 & 58 & 0 & 3 & 0 & 0 & 0 & 50 & 100 & 0 & 0 & 0 & 0 & 1 & 0 & 66 .\end{array}$ $\begin{array}{lllllllllllllllll}0 & 0 & 0 & 0 & 0 & 0 & 0 & 0 & 0 & 0 & 0 & 0 & 11 & 0 & 0 & 0 & 0\end{array}$ $\begin{array}{rrrrrrrrrrrrrrrrr}0 & 0 & 3 & 0 & 0 & 0 & 0 & 11 & 25 & 100 & 0 & 2 & 0 & 0 & 1 & 0 & 0\end{array}$

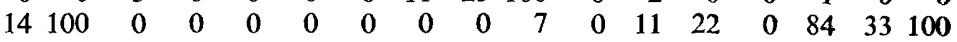

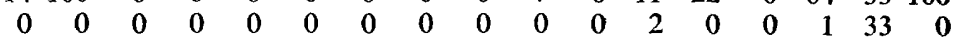

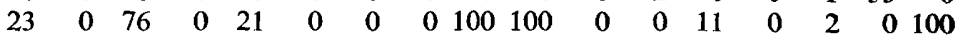
$\begin{array}{lllllllllllllllll}9 & 11 & 45 & 0 & 3 & 0 & 0 & 0 & 0 & 0 & 0 & 0 & 0 & 0 & 0 & 0 & 100\end{array}$ $\begin{array}{lllllllllllllllll}0 & 0 & 0 & 0 & 0 & 0 & 0 & 0 & 75 & 0 & 0 & 2 & 0 & 0 & 1 & 0 & 100\end{array}$

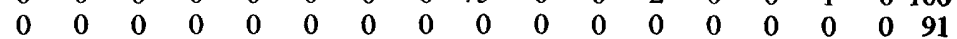


Table 4. (cont.)

Cluster

No. of strains

Alcohols utilized

1-Butanol

Ethanol

1-Propanol

D( - )-1,2-Propanediol

Glycerol

D-Arabitol

D-Mannitol

D-Sorbitol

meso-Inositol

Carboxylic acids utilized

Acetic acid

Butyric acid

Caproic acid

Caprylic acid

Lauric acid

Propionic acid

Valeric acid

Glutaric acid

Malonic acid

Succinic acid

Fumaric acid

Itaconic acid

DL-Glyceric acid

$\beta$-Hydroxybutyric acid

DL-Lactic acid

$\mathbf{L}(+)$-Tartaric acid

Citric acid

2-Ketogluconic acid

Pyruvic acid

2-Ketoglutaric acid

m-Hydroxybenzoic acid $76 \quad 0$

p)-Hydroxybenzoic acid 90100

Galacturonic acid

D-Gluconic acid

Amino acids utilized

L-Alanine

$\gamma$-Aminobutyric acid

L-Arginine

L-Asparagine

L-Aspartic acid

L-Cysteine

L-Cystine

Glycine

L-Leucine

L-Isoleucine

L-Methionine

L-Ornithine

L.-Phenylalanine

L-Proline

L-Serine

L-Threonine

L-Tryptophan

L-Tyrosine

L-Valine

Amines utilized

Histamine

$N$-Acetylglucosamine

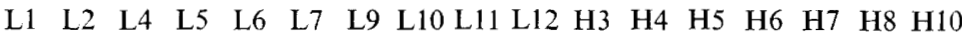

$\begin{array}{lllllllllllllllll}21 & 9 & 60 & 4 & 28 & 7 & 4 & 10 & 6 & 13 & 7 & 36 & 9 & 7 & 80 & 3 & 12\end{array}$ $\begin{array}{lllllllllllllllll}85 & 88 & 0 & 0 & 0 & 0 & 0 & 11 & 25 & 0 & 0 & 0 & 11 & 42 & 100 & 100 & 100\end{array}$

$\begin{array}{lllllllllllllllll}76 & 77 & 0 & 0 & 0 & 0 & 0 & 0 & 0 & 0 & 14 & 0 & 100 & 28 & 64 & 100 & 83\end{array}$

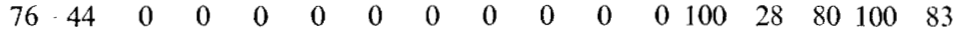

$\begin{array}{rllllllllllllllll}100 & 100 & 0 & 0 & 0 & 0 & 0 & 88 & 0 & 0 & 0 & 0 & 100 & 100 & 100 & 100 & 100\end{array}$

$\begin{array}{lllllllllllllllll}14 & 22 & 0 & 0 & 0 & 0 & 0 & 0 & 0 & 0 & 0 & 0 & 33 & 14 & 22 & 0 & 41\end{array}$

$\begin{array}{lllllllllllllllll}81 & 33 & 1 & 0 & 0 & 0 & 0 & 11 & 0 & 0 & 0 & 0 & 44 & 28 & 67 & 100 & 100\end{array}$

$\begin{array}{lllllllllllllllll}0 & 33 & 0 & 0 & 0 & 0 & 0 & 11 & 0 & 0 & 0 & 0 & 100 & 14 & 36 & 33 & 91\end{array}$

$\begin{array}{rrrrrrrrrrrrrrrrr}95 & 100 & 13 & 0 & 0 & 0 & 0 & 33 & 100 & 100 & 0 & 0 & 44 & 42 & 100 & 100 & 33\end{array}$

$\begin{array}{lllllllllllllllll}71 & 100 & 0 & 0 & 0 & 0 & 0 & 0 & 0 & 0 & 0 & 0 & 11 & 0 & 77 & 33 & 41\end{array}$

$\begin{array}{lllllllllllllllll}0 & 0 & 0 & 0 & 0 & 0 & 0 & 0 & 0 & 0 & 0 & 0 & 11 & 0 & 0 & 33 & 33\end{array}$

$\begin{array}{rrrrrrrrrrrrrrrrr}95 & 55 & 16 & 0 & 3 & 28 & 25 & 77 & 100 & 100 & 0 & 0 & 55 & 85 & 98 & 100 & 58\end{array}$

$\begin{array}{rrrrrrrrrrrrrrrrr}9 & 0 & 0 & 0 & 0 & 0 & 0 & 0 & 0 & 0 & 0 & 0 & 0 & 0 & 1 & 0 & 33\end{array}$

$\begin{array}{rrrrrrrrrrrrrrrrr}28 & 88 & 0 & 0 & 0 & 0 & 0 & 0 & 100 & 100 & 0 & 0 & 11 & 0 & 84 & 0 & 66\end{array}$

$\begin{array}{lllllllllllllllll}95 & 88 & 0 & 0 & 0 & 0 & 0 & 0 & 0 & 0 & 0 & 0 & 100 & 42 & 100 & 100 & 83\end{array}$

$\begin{array}{rrrrrrrrrrrrrrrrr}0 & 0 & 0 & 0 & 0 & 0 & 0 & 0 & 0 & 0 & 0 & 0 & 0 & 0 & 2 & 33 & 0\end{array}$

$\begin{array}{rrrrrrrrrrrrrrrrr}0 & 0 & 0 & 0 & 0 & 14 & 0 & 0 & 0 & 0 & 0 & 0 & 0 & 0 & 0 & 0 & 16\end{array}$

$\begin{array}{lllllllllllllllll}85 & 44 & 2 & 0 & 0 & 0 & 0 & 0 & 50 & 100 & 0 & 0 & 0 & 0 & 42 & 66 & 16\end{array}$

$\begin{array}{lllllllllllllllll}0 & 0 & 0 & 0 & 0 & 0 & 0 & 0 & 0 & 0 & 0 & 0 & 0 & 0 & 0 & 0 & 16\end{array}$

$\begin{array}{rrrrrrrrrrrrrrrrr}100 & 100 & 6 & 0 & 0 & 28 & 100 & 100 & 100 & 15 & 0 & 0 & 88 & 100 & 84 & 100 & 100 \\ 100 & 100 & 0 & 0 & 0 & 0 & 0 & 62 & 25 & 0 & 0 & 0 & 44 & 85 & 96 & 100 & 83\end{array}$

$\begin{array}{lllllllllllllll}0 & 0 & 0 & 0 & 0 & 0 & 0 & 0 & 0 & 0 & 0 & 0 & 15 & 100 & 100\end{array}$

$\begin{array}{rrrrrrrrrrrrrrr}4 & 0 & 3 & 0 & 0 & 0 & 0 & 0 & 0 & 0 & 0 & 0 & 0 & 0 & 0\end{array}$

$\begin{array}{lllllllllllllllll}0 & 0 & 0 & 0 & 0 & 0 & 0 & 0 & 0 & 69 & 0 & 2 & 11 & 0 & 2 & 0 & 16\end{array}$

$\begin{array}{lllllllllllllllll}85 & 66 & 0 & 0 & 0 & 0 & 0 & 100 & 25 & 0 & 0 & 0 & 0 & 100 & 92 & 100 & 0\end{array}$

$\begin{array}{lllllllllllllllll}81 & 100 & 0 & 0 & 0 & 0 & 0 & 90 & 0 & 0 & 0 & 0 & 0 & 100 & 95 & 50 & 8\end{array}$

$\begin{array}{lllllllllllllllll}28 & 55 & 31 & 0 & 0 & 0 & 0 & 0 & 0 & 0 & 0 & 0 & 0 & 0 & 50 & 0 & 33\end{array}$

$\begin{array}{rrrrrrrrrrrrrrrrr}28 & 0 & 0 & 0 & 0 & 0 & 0 & 40 & 0 & 0 & 0 & 0 & 0 & 14 & 12 & 50 & 50\end{array}$

$\begin{array}{rrrrrrrrrrrrrrrrr}33 & 88 & 30 & 0 & 17 & 0 & 0 & 90 & 25 & 92 & 0 & 0 & 0 & 100 & 39 & 100 & 50\end{array}$

$\begin{array}{lllllllllllllllll}42 & 44 & 0 & 0 & 0 & 0 & 0 & 10 & 0 & 0 & 0 & 0 & 22 & 0 & 45 & 100 & 16\end{array}$

$\begin{array}{lllllllllllllllll}28 & 55 & 0 & 0 & 0 & 0 & 0 & 0 & 0 & 0 & 0 & 0 & 11 & 0 & 6 & 0 & 33\end{array}$

$\begin{array}{rrrrrrrrrrrrrrrrr}0 & 0 & 0 & 0 & 0 & 0 & 0 & 0 & 0 & 0 & 0 & 0 & 0 & 0 & 1 & 0 & 0\end{array}$

$\begin{array}{lllllllllllllllll}0 & 0 & 0 & 0 & 0 & 0 & 0 & 0 & 0 & 0 & 0 & 0 & 22 & 0 & 1 & 0 & 50\end{array}$

$\begin{array}{lllllllllllllllll}0 & 0 & 0 & 0 & 0 & 0 & 0 & 0 & 0 & 0 & 0 & 0 & 55 & 0 & 1 & 0 & 66\end{array}$

$\begin{array}{lllllllllllllllll}0 & 0 & 0 & 0 & 0 & 0 & 0 & 0 & 0 & 0 & 0 & 0 & 0 & 0 & 5 & 0 & 0\end{array}$

$\begin{array}{lllllllllllllllll}57 & 55 & 0 & 0 & 3 & 0 & 0 & 0 & 0 & 0 & 0 & 0 & 0 & 28 & 74 & 50 & 58\end{array}$

$\begin{array}{rrrrrrrrrrrrrrrrr}0 & 0 & 0 & 0 & 0 & 0 & 0 & 0 & 0 & 0 & 0 & 0 & 0 & 0 & 8 & 0 & 0\end{array}$

$\begin{array}{rrrllllllllllllll}42 & 55 & 0 & 0 & 0 & 0 & 0 & 10 & 50 & 0 & 0 & 0 & 22 & 28 & 70 & 0 & 16\end{array}$

$\begin{array}{rrrrrrrrrrrrrrrrr}93 & 22 & 0 & 0 & 0 & 0 & 0 & 50 & 0 & 0 & 0 & 0 & 0 & 50 & 30 & 0 & 91\end{array}$

$\begin{array}{lllllllllllllllll}81 & 0 & 0 & 0 & 0 & 0 & 0 & 0 & 0 & 0 & 0 & 0 & 0 & 0 & 10 & 100 & 8\end{array}$

$\begin{array}{lllllllllllllllll}71 & 0 & 0 & 0 & 0 & 0 & 0 & 0 & 0 & 0 & 0 & 0 & 0 & 0 & 12 & 100 & 0\end{array}$

$\begin{array}{rrrrrrrrrrrrrrrrr}66 & 0 & 0 & 0 & 3 & 0 & 0 & 0 & 0 & 0 & 0 & 0 & 11 & 0 & 10 & 100 & 0 \\ 0 & 0 & 0 & 0 & 0 & 0 & 0 & 0 & 0 & 0 & 0 & 0 & 14 & 0 & 0 & 0 & 0\end{array}$

The following substrates were not utilized by any cluster: L-rhamnose, 2-propanol, dulcitol, phenol, 2-phenylethanol, benzoic acid, ascorbic acid, o-hydroxybenzoic acid, stearic acid, L-lysine, $\alpha$-amylamine, ethanolamine, putrescine, guanine, thymine, $n$-hexadecane, $n$-pentadecane, $n$-phenyldecane, pristane, pentadecylcyclohexane.

All isolates were facultative anaerobes.

* The 'percentage positive' calculations do not include missing data, so for some tests the product of the feature frequency and the total number of organisms in the cluster is not an integral number. 
From the 27 original clusters, 47 representative strains were chosen ( 3 from each of the 10 largest clusters and 1 from each of the others). Cluster analyses failed to show similarity $(75 \%)$ between the $4{ }^{\circ} \mathrm{C}$ and $20^{\circ} \mathrm{C}$ clusters. Thus, the populations isolated at $4{ }^{\circ} \mathrm{C}$ appear to be distinct from those isolated at $20^{\circ} \mathrm{C}$. Tests on the 47 representative strains were repeated at $5{ }^{\circ} \mathrm{C}$ since even identical organisms can show different test results at $5^{\circ} \mathrm{C}$ and 20 C. However, less than $3 \%$ of the repeated test results differed from the original results for both the $4{ }^{\circ} \mathrm{C}$ and $20^{\circ} \mathrm{C}$ isolates.

\section{Distribution of clusters}

The distribution of the clusters is shown in Figs 2 and 3 for the $4{ }^{\circ} \mathrm{C}$ and $20^{\circ} \mathrm{C}$ isolates, respectively. Some of the clusters (L1, L4, L6, H4, H7) were widely distributed geographically in water and sediment, but most clusters showed restricted distribution, e.g. cluster L12 contained only strains from sediment near Point Barrow. The distribution pattern of clusters was similar in Prudhoe Bay water samples (stations 55, 70, 71).

\section{Classification of clusters}

The features of the major clusters are shown in Table 4. The growth factor requirements for all clusters are shown in Table 5 . None of the isolates clustered with the reference strains and none was identified by the probabalistic identification matrices. The Beaufort Sea isolates are not identical with the common Gram-negative rods (some of which are from marine sources) contained in the matrices.

Of the 27 phenotypic clusters, 22 could be placed into seven categories:

1. Gram-negative rods producing yellow or orange pigments (clusters L3, L4, L6, H1, H2, $\mathrm{H} 3, \mathrm{H} 4, \mathrm{H} 5, \mathrm{H} 13$ ). According to the 8th edition of Bergey's Manual (Buchanan \& Gibbons, 1974), Gram-negative, facultatively anaerobic rods, motile or non-motile, producing yellow, orange, red or brown pigments are classified in the genus Flavobacterium. This definition is vague and encompasses a heterogeneous collection of bacteria, e.g. it could include yellow-pigmented members of the Enterobacteriaceae. There were morphological, physiological, biochemical and nutritional differences between the Flavobacterium type strains in Bergey's Manual and our isolates. Many of our strains showed pleomorphism characteristic of Cytophaga species: however, no swarming was observed. The distinction between Flavobacterium and Cytophaga may be difficult (Hayes, 1963; Weeks, 1969; Hendrie et al., 1968). Several studies have attempted to clarify the taxonomy of yellowpigmented Gram-negative bacteria (Goodfellow et al., 1976; Floodgate \& Hayes, 1963). Clearly, this group of organisms is quite heterogeneous.

2. Gram-negative bacteria forming full or partial rings (clusters L5, H6, H9). These organisms are morphologically similar to members of the genus Microcyclus, which is heterogeneous (Claus et al., 1968; Raj, 1977) and of uncertain affiliation (Buchanan \& Gibbons, 1974). Our strains have different physiological and nutritional characteristics from previously described species. Unlike Microcyclus marinus and several non-marine Microcyclus species (Raj, 1977), our strains grew at $5^{\circ} \mathrm{C}$ and did not produce acids from carbohydrates.

3. Gram-negative, non-pigmented, fermentative, facultatively anaerobic, curved or straight rods (clusters L7, L8). The morphological and biochemical characteristics of these organisms closely resembled those of Vibrio species (Davis \& Park, 1962) or Beneckea species (Baumann et al., 1971). All of the clustered organisms in this category were obligate psychrophiles. They had more complex growth requirements than the psychrophilic Vibrio marinus (Colwell \& Morita, 1964) isolated from the North Pacific Ocean (Morita \& Haight, 1964).

4. Gram-negative, non-pigmented, weakly fermentative, facultatively anaerobic, highly pleomorphic rods (clusters L1, L2, H7, H8). This category of clusters has not been identified 
Table 5. Growth factor requirements of dominant clusters of bacterial populations isolated at 4 and $20^{\circ} \mathrm{C}$

\begin{tabular}{|c|c|c|c|c|c|c|c|c|c|c|c|c|c|c|}
\hline Cluster & 1 & 2 & 3 & 4 & 5 & 6 & 7 & 8 & 9 & 10 & 11 & 12 & 13 & $\begin{array}{c}14 \\
2\end{array}$ \\
\hline No. of strains & 21 & 9 & 2 & 60 & 4 & 28 & 7 & 2 & 4 & 10 & 6 & 13 & 2 & 2 \\
\hline \multicolumn{15}{|l|}{ Growth factor: } \\
\hline Type 1 & - & - & - & - & - & - & - & - & - & + & + & - & - & + \\
\hline Type 2 & + & + & + & + & - & - & - & + & + & - & - & + & + & \\
\hline Type 3 & - & - & - & - & \pm & \pm & + & - & - & - & - & - & - & \\
\hline Type 4 & - & - & - & - & $\overline{\mathrm{w}}$ & $\overrightarrow{\mathrm{w}}$ & - & - & - & - & - & - & - & \\
\hline \multicolumn{14}{|c|}{$20^{\circ} \mathrm{C}$ isolates: $\mathrm{H}$ series } & \\
\hline Cluster & 1 & 2 & 3 & 4 & 5 & 6 & 7 & 8 & 9 & 10 & 11 & 12 & 13 & \\
\hline No. of strains & 2 & 2 & 7 & 36 & 9 & 7 & 80 & 3 & 2 & 12 & 2 & 2 & 2 & \\
\hline \multicolumn{14}{|l|}{ Growth factor: } & \\
\hline Type 1 & - & - & - & - & - & - & - & - & - & - & - & + & + & \\
\hline Type 2 & - & - & - & - & + & + & + & + & + & + & + & - & - & \\
\hline Type 3 & - & + & - & + & - & - & - & - & - & - & - & - & - & \\
\hline Type 4 & + & - & + & - & - & - & - & - & - & - & - & - & - & \\
\hline
\end{tabular}

with any genus described in Bergey's Manual. These non-motile organisms could be associated with several different genera.

5. Gram-negative, non-pigmented, non-fermentative, aerobic rods (cluster L10). This category has not been identified. These organisms reduce nitrate and are probably capable of anaerobic respiration. Phenotypically, they could belong to the genera Pseudomonas, Alcaligenes or Alteromonas (Baumann et al., 1972). With no observed motility and without flagella determination, the distinction is not clear.

6. Non-acid fast, coryneform bacteria showing rudimentary branching and snapping division (cluster H10). The coryneform bacteria may be Arthrobacter species even though they appeared to be Gram-negative. Indeed, many Arthrobacter species fail to appear Gram-positive (Mulder, 1964). Coccoid forms of these organisms and morphogenesis typical of Arthrobacter were observed.

7. Gram-negative coccobacilli (clusters H11, H12). By the criteria of Baumann et al. (1968), the strains in cluster H12 appear to be Acinetobacter species. Cluster H11 is not closely related phenotypically and remains unidentified. Organisms in cluster $\mathrm{H} 12$ were oxidase-negative, did not require growth factors and utilized many substrates including hydrocarbons. Hydrocarbon utilization by Acinetobacter has been reported by Finnerty et al. (1973).

\section{DISCUSSION}

The Arctic Beaufort Sea, like other polar seas, is characterized by low temperatures, extensive ice cover, constant sunlight during summer and constant darkness during winter. Bacteria in the Beaufort Sea are adapted to these extreme environmental conditions. Our isolates clearly showed adaptation to growth at low temperatures. Of the $4{ }^{\circ} \mathrm{C}$ isolates, $25 \%$ were obligate psychrophiles unable to grow above $15{ }^{\circ} \mathrm{C}$. The remainder of the $4{ }^{\circ} \mathrm{C}$ isolates and all of the $20^{\circ} \mathrm{C}$ isolates were psychrotrophs; $95 \%$ of these could not grow at $37^{\circ} \mathrm{C}$. In comparison to our findings, McDonald et al. (1963) found $31 \%$ of their isolates from Canadian Arctic sediments could grow at $0{ }^{\circ} \mathrm{C}$ but not at $25^{\circ} \mathrm{C}$. In studies in the Antarctic Ocean, Wiebe \& Hendricks (1974) found $37 \%$ of their $4{ }^{\circ} \mathrm{C}$ isolates could not grow above $15{ }^{\circ} \mathrm{C}$ and Morita (1975) reported that $35 \%$ of his isolates could not grow at $20^{\circ} \mathrm{C}$. Thus, the Arctic and Antarctic seas are dominated by psychrotrophs and have a high incidence of obligate psychrophiles.

Nearshore areas of the Beaufort Sea show large seasonal fluctuations in salinity. Summer 
freshwater input and ice melt result in low salinities. Freezing out of salts during winter ice formation results in hypersaline layers which move to the bottom. Most of our isolates could not grow without added $\mathrm{NaCl}$. The optimum salt concentration was $3 \%(\mathrm{w} / \mathrm{v}) \mathrm{NaCl}$. Most of the $20^{\circ} \mathrm{C}$ isolates tolerated a wide range of salt concentrations, but many of the $4{ }^{\circ} \mathrm{C}$ water isolates were restricted to near $3 \%(\mathrm{w} / \mathrm{v}) \mathrm{NaCl}$ for growth.

We are not certain why so many strains were oxidase-negative. It is possible that test conditions, e.g. age of cultures, affected the results. Using identical methods in a number of other studies, we have observed much higher proportions of oxidase-positive organisms.

All isolates were facultative anaerobes by the agar-butt stab method. The oxidative/ fermentative metabolism tests on MOF medium were used to distinguish aerobes from facultative anaerobes.

Pigmentation can protect bacteria against the lethal effects of intense solar radiation (Mathews \& Sistrom, 1959). A very high proportion of the bacterial isolates obtained from surface waters at $4{ }^{\circ} \mathrm{C}$ were pigmented; it is possible that the orange or yellow pigmentation is an adaptive protective mechanism for Beaufort Sea bacteria exposed to intense sunlight during the Arctic summer.

An unexpected finding was that most bacteria required vitamins or more complex growth factors. The probable source of nutrients for Beaufort Sea bacteria is primary producing phytoplankton. The annual spring bloom of under-ice algae is probably the prime source of nutrients for bacterial growth (Horner \& Alexander, 1972). Phytoplankton are known producers of vitamins and amino acids which can supply bacterial growth factor requirements (Carlucci \& Bowes, 1970; MacLeod et al., 1954; Burkholder \& Burkholder, 1956). Some flavobacteria have complex requirements for vitamins and amino acids (Prince et al., 1954; Prince \& Cleverdon, 1955; Weeks \& Beck, 1960).

The cluster analyses and comparison with previously described taxa indicate that the dominant bacteria of the Beaufort Sea are quite different from those found in temperate marine environments. Most of the phenotypic clusters could be tentatively classified as members of genera which are listed as of uncertain affiliation in Bergey's Manual (Buchanan \& Gibbons, 1974). Pseudomonas species, which are often found to be a dominant genus in marine environments (Simidu et al., 1977; Pfister \& Burkholder, 1965; Murchelano \& Brown, 1970), did not comprise a large proportion of the Beaufort Sea bacteria. We did find several clusters of presumed Vibrio species; such species have been found in high proportions in temperate marine environments (Kaneko \& Colwell, 1973, 1974; Lovelace et al., 1967; Cook \& Goldman, 1976). Flavobacteria are usually not the dominant taxa in temperate marine ecosystems. In Chesapeake Bay, Lovelace et al. (1967) found $56 \%$ Vibrio, 18\% Pseudomonas and 6\% Flavobacterium species. In Antarctic marine waters, Pfister \& Burkholder (1965) found Pseudomonas species to be dominant and pigmented bacteria to comprise a low proportion of the bacterial population. The latter study, in another polar marine environment, contrasts with our findings.

With respect to the genera represented in our cluster analyses, the species were psychrophilic or psychrotrophic. In many cases these may represent new species. The environmental conditions of the Beaufort Sea have apparently resulted in selection of heterogeneous bacterial taxa that are uniquely adapted as members of the bacterial community capable of survival and proliferation in this ecosystem.

This study was supported by the Bureau of Land Management through interagency agreement with the National Oceanic and Atmospheric Administration under which a multi-year program, responding to needs of petroleum development of the Alaskan continental shelf, is managed by the Outer Continental Shelf Environmental Assessment Program (OCSEAP) Office. We wish to thank T. S. Kaneko for laboratory assistance, E. J. Krichevsky for performing the computer manipulations and C. A. Walczak for assistance with the computer programs. 


\section{REFERENCES}

Barber, M. \& Kuper, S. W. A. (1951). Identification of Staphylococcus pyogenes by the phosphatase reaction. Journal of Pathology and Bacteriology 63, 65-68.

Baumann, P., Doudoroff, M. \& Stanier, R. Y. (1968). A study of the Moraxella group. II. Oxidase-negative species (genus Acinetobacter). Journal of Bacteriology 95, 1520-1541.

Baumann, P., Baumann, L. \& Mandel, M. (1971). Taxonomy of marine bacteria: the genus Beneckea. Journal of Bacteriology 107, 268-294.

Baumann, L., Baumann, P., Mandel, M. \& Allen, R. D. (1972). Taxonomy of aerobic eubacteria. Journal of Bacteriology 110, 402-429.

Buchanan, R. E. \& Gibbons, N. E. (editors) (1974). Bergey's Manual of Determinative Bacteriology, 8th edn. Baltimore: Williams \& Wilkins.

Burkholder, P. R. \& BuRKHOLder, L. M. (1956). Vitamin $B_{12}$ in suspended solids and marsh muds collected along the coast of Georgia. Limnology and Oceanography 1, 202-208.

Carlucci, A. F. \& EOWES, P. M. (1970). Vitamin production and utilization by phytoplankton in mixed culture. Journal of Phycology 6, 393-400.

Claus, D., bergendahl, J. E. \& Mandel, M. (1968). DNA base composition of Microcyclus species and organisms of similar morphology. Archiv für Mikrobiologie 63, 26-68.

Colwell, R. R. \& Morita, R. Y. (1964). Reisolation and emendation of description of Vibrio marinus (Russell) Ford. Journal of Bacteriology 88, 831-837.

Cook, T. M. \& Goldman, C. K. (1976). Bacteriology of Chesapeake Bay surface waters. Chesapeake Science 17, 40-49.

Davis, H. G. \& Park, R. W. A. (1962). A taxonomic study of certain bacteria currently classified as Vibrio species. Journal of General Microbiology 27, 101-119.

Finnerty, W. R., Kennedy, R. S., Spurlock, B. O. \& YovNG, R. A. (1973). Microbes and petroleum: perspectives and implications. In The Microbial Degradation of Oil Pollutants, pp. 105-125. Edited by D. G. Ahearn \& S. P. Meyers. Baton Rouge: Center for Wetland Resources. Louisiana State University Publication No. LSU-SG-73-01.

Floodiate, G. D. \& Hayes, P. R. (1963). The Adansonian taxonomy of some yellow pigmented marine bacteria. Journal of General Microbiology 30, 237-244.

Goodfellow, M., Austin, B. \& Dickinson, C. H. (1976). Numerical taxonomy of some yellowpigmented bacteria isolated from plants. Journal of General Microbiology 97, 219-233.

HAYES, P. R. (1963). Studies on marine flavobacteria. Journal of General Microbiology 30, 1-19.

Hendrie, M. S., Mitchell, T. G. \& Shewan, J. M. (1968). The identification of yellow-pigmented rods. In Identification Methods for Microbiologists, Part B, pp. 67-78. Edited by B. M. Gibbs \& D. A. Shapton. London: Academic Press.

Horner, R. \& Alexander, V. (1972). Algal populations in Arctic sea ice: an investigation of heterotrophy. Limnology and Oceanography 17, 454-458.
KaneKo, T. \& Colwell, R. R. (1973). Ecology of Vibrio parahaemolyticus in Chesapeake Bay. Journal of Bacteriology 113, 24-32.

Kaneko, T. \& ColWell, R. R. (1974). Distribution of Vibrio parahaemolyticus and related organisms in the Atlantic Ocean off South Carolina and Georgia. Applied Microbiology 28, 1009-1017.

Kaneko, T., Holder-Franklin, M. \& Franklin, M. (1977a). Multiple syringe inoculator for agar plates. Applied and Environmental Microbiology 33, 982-985.

Kaneko, T., Atlas, R. \& Krichevsky, M. (1977b). Bacterial diversity in the Beaufort Sea. Nature, London 270, 596-599.

KRICHEVSKY, M. (1977). Coding and management of microbiological data. Developments in Industrial Microbiology 18, 309-318.

LEIFSON, E. (1963). Determination of carbohydrate metabolism of marine bacteria. Journal of Bacteriology 85, 1183-1184.

Liston, J., Wiebe, W. \& Colwell, R. R. (1963). Quantitative approach to the study of bacterial species. Journal of Bacteriology 85, 1061-1070.

lovelace, T. E., Tubiash, H. \& Colwell, R. R. (1967). Quantitative and qualitative commensal bacterial flora of Crassostrea virginica in Chesapeake Bay. Proceedings of the National Shellfisheries Association 58, 82-87.

Macleod, R. A., Onofrey, E. \& Norris, M. E. (1954). Nutrition and metabolism of marine bacteria. I. Survey of nutritional requirements. Journal of Bacteriology 68, 680-686.

Mathews, M. M. \& Sistrom, W. R. (1959). Function of carotenoid pigments in non-photosynthetic bacteria. Nature, London 184, 1892-1893.

McDonald, I. J., Quadling, C. \& Chambers, A. K. (1963). Proteolytic activity of some cold-tolerant bacteria from Arctic sediments. Canadian Journal of Microbiology 9, 303-315.

Morita, R. Y. (1975). Psychrophilic bacteria. Bacteriological Reviews 39, 144-167.

Morita, R. Y. \& Haight, R. D. (1964). Temperature effects on the growth of an obligate psychrophilic marine bacterium. Limnology and Oceanography 9, 103-106.

Mulder, E. G. (1964). Arthrobacter. In Principle and Application in Aquatic Microbiology, Proceedings of Rudolfs Research Conference, pp. 254. 276. Edited by H. Heukelekian \& N. C. Dondero. New York: John Wiley.

Murchelano, R. A. \& Brown, C. (1970). Heterotrophic bacteria in Long Island Sound. Marine Biology 7, 1-6.

Pfister, R. M. \& Burkholder, P. R. (1965). Numerical taxonomy of some bacteria isolated from antarctic and tropical seawaters. Journal of Bacteriology 90, 863-872.

Prince, H. N. \& Cleverdon, R. C. (1955). The flavobacteria. II. Utilization of nitrogen compounds. Journal of Bacteriology 69, 307-309.

Prince, H. N., Beck, E. S., Cleverdon, R. C. \& KulP, W. L. (1954). The flavobacteria. I. Nutritional requirements. Journal of Bacteriology 68, 326-328. 
RAJ, H. D. (1977). Microcyclus and related ringforming bacteria. CRC Critical Reviews in Microbiology 5, 243-269.

Rogosa, M., Krichevsky, M. I. \& Colwell, R. R. (1971). Method for coding data on microbial strains for computer manipulation. International Jounal of Systematic Bacteriology, Supplement 21, 1A-184A.

Sierra, G. (1957). A simple method for the detection of lipolytic activity of microorganisms and some observations on the influence of contact between cells and fatty substrates. Antonie van Le'uwenhoek 23, 15-22.

Simidu, U., KaneKo, E. \& Taga, N. (1977). Microbiological studies of Tokyo Bay. Microbial Ecology 3, 173-191.

Skerman, V. B. D. (1969). Abstracts of Microbiological Methods. New York: Wiley-Interscience.

SOCIETY OF AMERICAN BACTERIOLOGISTS (1957). Manual of Microbiological Methods. New York: McGraw-Hill.

Sokal, R. R. \& Sneath, P. H. A. (1963). Principles of Numerical Taxonomy. San Francisco: W. H. Freeman.

Stanier, R. Y., Palleroni, N. J. \& Doudoroff, M.
(1966). The aerobic pseudomonads: a taxonomic study. Journal of General Microbiology 43, 159271.

WalczaK, C. A. \& Krichevsky, M. I. (1977). Interactive computer editing of phenetic data for numerical taxonomy. American Society for Microbiology Annual Meeting, abstract no. 138.

WalczaK, C. A., Johnson, R. \& KRICHEVSKy, M. I. (1978). A flexible approach to phenotypic feature frequency calculations. American Society for Microbiology Annual Meeting, abstract no. 156.

WeEks, O. B. (1969). Problems concerning the relationships of cytophaga and flavobacteria. Journal of Applied Bacteriology 32, 13-18.

WeEks, O. B. \& Beck, S. M. (1960). Nutrition of Flavobacterium aquatile strain Taylor and a microbiological assay for thiamine. Journal of General Microbiology 23, 217-229.

Wiebe, W. J. \& Hendricks, C. W. (1974). Distribution of heterotrophic bacteria in a transit of the Antarctic Ocean. In Effect of the Ocean Environment on Microbial Activities, pp. 524-535. Edited by R. R. Colwell \& R. Y. Morita. Baltimore: University Park Press. 